\title{
OPTIMIZATION AND FATIGUE ANALYSISOF A CRANE HOOK USING FINITE ELEMENT METHOD
}

\author{
Amandeep Singh, Vinod Rohilla \\ Department of Mechanical Engineering, Chandigarh College of Engineering and \\ Technology,Panjab University,Chandigarh,India
}

\begin{abstract}
Stress analysis plays an important role in the design of structures like crane hook under loading conditions. Crane hook is a reliable lifting component being used in industries. Structure failure of crane hook occurs because of the stress induced due to repetitive loading and unloading conditions. In this study, solid modeling of crane hook having trapezoidal cross-section referring to one of its existing design is done using SOLIDWORKS. Further, analyses are carried out in ANSYS Workbench and nCode DesignLife. The lengths of two parallel sides of the cross-section of crane hook are varied and different candidates are obtained for loading capacity of 30 ton on the basis of Mass, total Displacement and Von-Mises stress.This is done to reduce weight and balance economy. Further, out of these candidates, best candidates are considered and fatigue analysis is performed on these candidates.
\end{abstract}

\section{KEYWORDS}

Crane hook, weight optimization, Finite Element Analysis, structural analysis, fatigue analysis.

\section{INTRODUCTION}

The structure strength is an important signal to response the load bearing capability of the elevating equipment.Crane hook is a curved bar and is used for lifting loads in cranes. In order to reduce structure failure of crane hook, induced stress in crane hook is analyzed properly. Fatigue damage is the initiation of a crack due to fluctuating loading. It is caused due to stress levels which are insufficient to cause damage in a single application [1]. It is highly responsible and important component being used for industrial works. It is a hoisting fixture manufactured and designed to engage a link of a chain or ring or the pin of a cable socket or shackle and safety guidelines must be followed [2]. In the present work, study of different candidates of crane hook of trapezoidal cross section based on design parameters are carried out and weight optimization is carried out by varying the design parameters. The present study shows the deformation and fatigue life contour plots of crane hook using Ansys Workbench and Ansys nCode DesignLife.

\subsection{Algorithms To Be Followed For Fatigue Analysis}

\subsubsection{Mean Stress Effects:}

Alternating peak stress range is the primary influence on fatigue life. Mean stress that occurs during the loading is a secondary effect. Tensile mean stresses reduce fatigue life and compressive mean stresses increase fatigue life which is commonly ignored. Goodman and Gerber theories are based on the assumption that the alternating stress range and tensile mean

DOI : 10.14810/ijmech.2015.4403 
stress are either linearly (Goodman) or parabolically(Gerber) related [3]. The material with percentage elongation greater than $5 \%$ is ductile in nature and material with percentage elongation lesser than 5\% is brittle in nature [4]. The material selected has elongation greater than $5 \%$ and is ductile in nature [5]. Therefore the theory considered is Gerber which is best suited for ductile materials [6].

\subsubsection{Stress Combination Method:}

The analysis cell creates a stress tensor history [7],

$$
\sigma_{\mathrm{ij}}=\left[\begin{array}{lll}
\sigma_{\mathrm{xx}} & \sigma_{\mathrm{xy}} & \sigma_{\mathrm{zx}} \\
\sigma_{\mathrm{xy}} & \sigma_{\mathrm{yy}} & \sigma_{\mathrm{yz}} \\
\sigma_{\mathrm{zx}} & \sigma_{\mathrm{yz}} & \sigma_{\mathrm{zz}}
\end{array}\right]
$$

But for fatigue calculation, this stress tensor should be reduced to a scalar value, so that it can be cycle counted and the resulting cycles can be compared to an S-N curve or curves. This method is called Stress combination. Signed von mises is the stress combination method used which is same as Von-mises but it takes the sign of absolute maximum principal stress [7], i.e.,

$$
\sigma_{\mathrm{SVM}}=\frac{\sigma_{\mathrm{AMP}}}{\left|\sigma_{\mathrm{AMP}}\right|} \cdot \sqrt{\frac{\left(\sigma_{1}-\sigma_{2}\right)^{2}+\left(\sigma_{2}-\sigma_{3}\right)^{2}+\left(\sigma_{3}-\sigma_{1}\right)^{2}}{2}}
$$

Where, $\sigma_{\mathrm{SVM}}=$ signed von-mises stress.

$\sigma_{\mathrm{AMP}}=$ absolute maximum principal stress.

$\sigma_{1}, \sigma_{2}, \sigma_{3}=$ principal stresses.

Von-mises criterion is used for estimating the failure of ductile materials [8]. As the equivalent stress given by the von mises criterion is always positive and lacks direction, it cannot identify compressive mean stresses. In order to overcome these drawbacks, signed von-mises is used [7, 9].

\subsubsection{Surface Effects:}

Surface treatment and finish can have a remarkable effect on fatigue strength. The fatigue strength in general is reduced due to machining marks i.e., rough surface finishes, whereas surface treatments are applied to improve the fatigue strength. Designlife considers the effect of surface treatment and finish together as one Surface Factor $\left(\mathrm{K}_{\text {sur }}\right)$. This surface factor is applied for the adjustment of the material curve and it is the product of three factors [7]:

$$
\mathrm{K}_{\text {sur }}=\mathrm{K}_{\text {treatment }} * \mathrm{~K}_{\mathrm{user}} * \mathrm{~K}_{\text {roughness }}
$$

Where, $\mathrm{K}_{\text {treatment }}=$ surface treatment factor

$\mathrm{K}_{\mathrm{user}}=$ user surface factor

$\mathrm{K}_{\text {roughness }}=$ surface roughness factor 
Both $\mathrm{K}_{\text {treatment }}$ and $\mathrm{K}_{\mathrm{user}}$ are taken as 1 [7]. $\mathrm{K}_{\text {roughness }}$ is based on the strength and type ofmaterial. The average surface roughness value $\left(R_{z}\right)$ for forging production methods is, $R_{z}=6.3 \mu \mathrm{m} \mathrm{[10]}$. Roughness factor $\left(\mathrm{K}_{\mathrm{r}}\right)$ is given by [7,11]:

$$
\mathrm{K}_{\mathrm{r}}=1-\mathrm{a} \underset{\mathrm{r}}{\log } \log \left(\mathrm{R}_{\mathrm{z}}\right) \log \left(\frac{2 \mathrm{R}_{\mathrm{M}}}{\mathrm{R}_{\mathrm{m}, \mathrm{N}, \mathrm{min}}}\right)
$$

Where, $\mathrm{R}_{\mathrm{M}}$ is Ultimate tensile strength (U.T.S) in MPa. a $\& \mathrm{R}_{\mathrm{m}, \mathrm{N}, \mathrm{min}}$ are constants and function of type of material and its Ultimate tensile strength (U.T.S). For AISI 4340 150, a $\underset{r}{r}=0.22$ $\& \mathrm{R}_{\mathrm{m}, \mathrm{N}, \min }=400$ [7].Therefore, value of $\mathrm{K}_{\mathrm{r}}$ obtained is 0.871 .

\section{LITERATURE SURVEY}

Spasoje Trifkovic' et al[12] worked on the stress state in the crane hook using exact and approximate methods. Stresses are calculated in various regions of the crane hook material by assuming crane hook as a straight beam and curved beam. Torres et al[13] worked on the causes which led to failure of the crane hook in service. This study shows the simulation of the thermal history of the hook and explains the standards governing the manufacturing. Nishant soni et al. [14] studied the optimization of low carbon steel for its self-weight and the component load. Objective of study was the optimization of the mass of crane hook under the effect of static load but no considerations of fatigue life are made. Finite element analysis (FEA) is used for the shape optimization of crane hook and validation of final geometry. Geometry and manufacturing constrain are also considered during optimization process and results show that optimized crane hook is $14 \%$ lighter than the original crane hook. Pradyumnakesharimaharana [15] estimated crane hook dimensions for various cross sections topology. This study shows that the trapezoidal cross section is least stressed.Mr. A Gopichand. Et al. [16] studied taguchi method that can be used for optimization of crane hook. In this work, three design parameters are considered and made mixed levels a L16 orthogonal array. Von-mises stress is determined for different combinations of input parameters and an optimum combination of input parameters for minimum Von-mises stress is considered. No consideration of fatigue life results of the component is made.Several attempts have been made in this field to achieve the objective of weight optimization. As per literature available, there is a lot of scope of weight optimization and cost reduction of crane hook by varying the design parameters on the basis of deformation contours and fatigue life results using finite element method (FEM).

\section{CRANE HOOK MODELLINGAND MATERIAL SELECTION}

\subsection{Hook Modelling Using Solid works:}

Curved bars are frequently subjected to axial or bending loads or a combination of both axial and bending loads [17]. The actual stresses in case of curved bars may be many times greater than that for straight bars. Computer Aided Design (CAD) is the very first stage of any project and the shapes drafted in CAD software will be considered in Finite Element Analysis (FEA) software for analysis. The design of crane hook is made in Solidworks. The dimensions of cross-section of the actual design of crane hook are given in the 2D drawing shown in fig. 1. The CAD model of crane hook is shown in fig. 2.The CAD model of crane hook is saved as a parasolid format with a file extension .x_t. This parasolid file is imported to Finite Element Analyses (FEA) software Ansys for structural and fatigue analysis. 


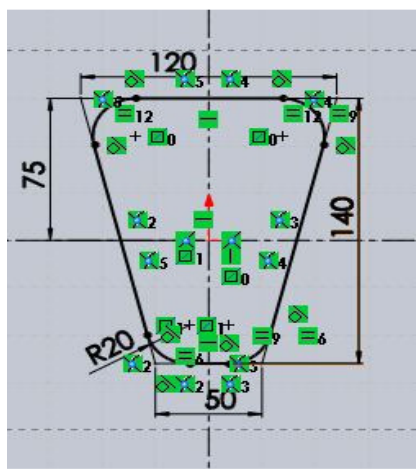

Fig.1 Dimensions (in mm) of trapezoidal cross-section.

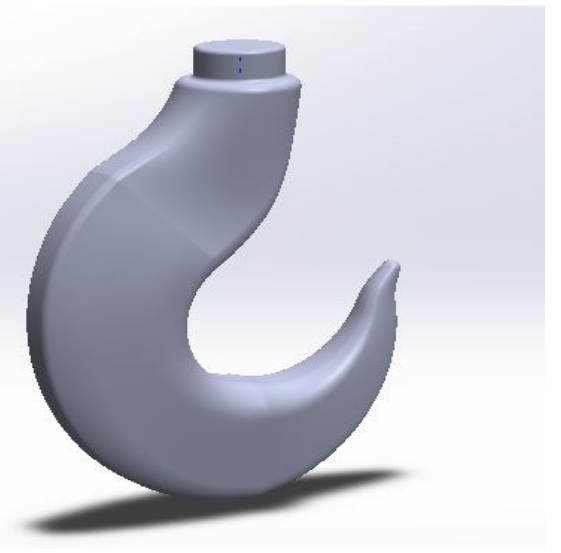

Fig. 2 Crane hook CAD model.

\subsection{Material Assigned}

In the present work, the material selected is AISI 4340 150. Along with the mechanical properties of AISI 4340 150, some fatigue parameters are also listed in the table 1. For this material, Numerical fatigue cutoff life is 1E8 i.e., damage due to fatigue will be assumed zero beyond this numerical fatigue cutoff life [7].

Table 1. Mechanical Properties of AISI 4340150

\begin{tabular}{|l|l|}
\hline Density & $7827 \mathrm{~kg} \mathrm{~m}^{-3}$ \\
\hline Young's modulus & $1.9995 \mathrm{E}^{11} \mathrm{~Pa}$ \\
\hline Poisson's ratio & 0.32 \\
\hline Bulk Modulus & $1.8514 \mathrm{E}^{11} \mathrm{~Pa}$ \\
\hline Shear Modulus & $7.5738 \mathrm{E}^{10} \mathrm{~Pa}$ \\
\hline Tensile Ultimate Strength & $1.0894 \mathrm{E}^{9} \mathrm{~Pa}$ \\
\hline Nfc(Numerical fatigue cutoff life) & $1 \mathrm{E}^{8}$ \\
\hline Ne(Endurance limit) & $1 \mathrm{E}^{6}$ \\
\hline
\end{tabular}




\section{STRUCTURAL AND FATIGUE ANALYSIS USING ANSYS WORKBENCH AND ANSYS NCODE DESIGNLIFE}

\subsection{Static Structure Analysis}

The first step in simulation process for structure analysis is to assign the material, apply boundary conditions and then generate mesh. A load of 30 ton is applied and the degree of freedom (DOF) of top of the crane hook is zero i.e., it is fully constrained as shown in fig. 4.Contour plots of equivalent (von-mises) stress and total deformation for actual design are shown in the fig. 5(a) and 5(b) respectively.

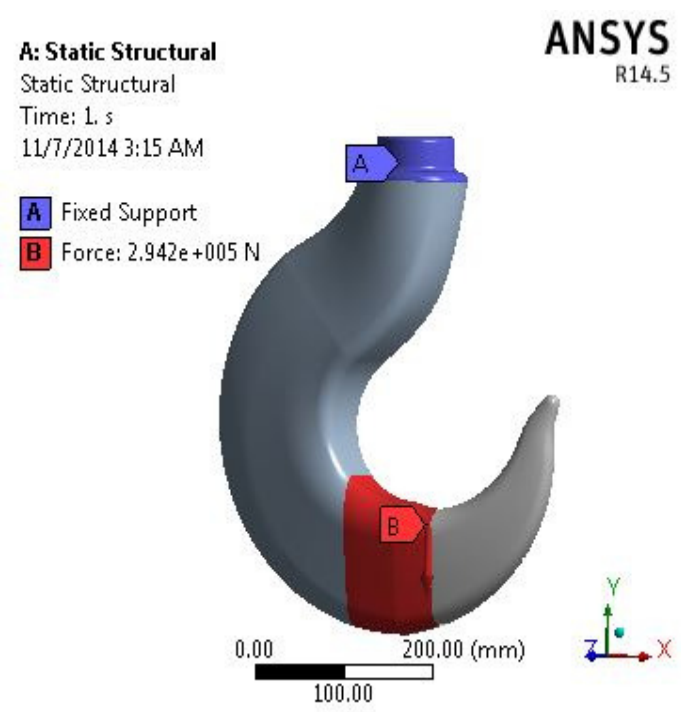

Fig. 4 Boundary Conditions.

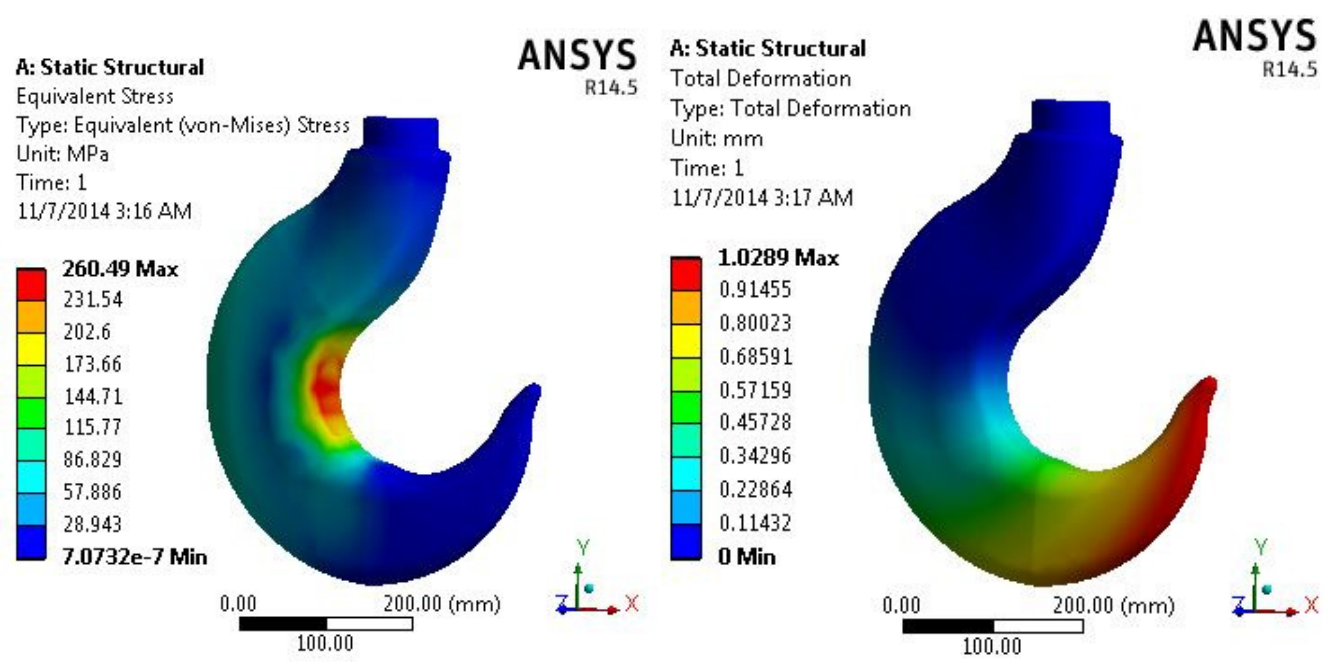

(a)

(b)

Fig. 5Equivalent (von mises) stress and Total deformation of actual crane hook. 
Further, two parallel sides of crane hook cross-section namely ' $D$ ' \& ' $d$ ' are taken as design variables where ' $\mathrm{D}$ ' is the inner side and ' $\mathrm{d}$ ' is the outer side of crane hook. The upper bound and lower bound of length of 'D'is $125 \mathrm{~mm}$ and $100 \mathrm{~mm}$ respectively whereas the value of ' $\mathrm{d}$ ' varies from $40 \mathrm{~mm}$ to $55 \mathrm{~mm}$. Table 2 . shows the mass, equivalent(von-mises) stress and total deformation results of the different candidates obtained.

The main objective of this study is weight optimization. Therefore, the objective importance of mass is considered higher. Based on this, best three candidates are selected out of the 24 candidates shown in table 3 .

Table 2. Comparison of mass, equivalent (von-mises) stress and total deformation results of different candidates.

\begin{tabular}{|c|c|c|c|c|c|}
\hline Trial No. & $\begin{array}{l}\text { Width, D } \\
(\mathrm{mm})\end{array}$ & $\begin{array}{l}\text { Width, d } \\
(\mathrm{mm})\end{array}$ & $\begin{array}{l}\text { Mass } \\
(\mathrm{kg})\end{array}$ & Stress (MPa) & $\begin{array}{l}\text { Displacement } \\
(\mathrm{mm})\end{array}$ \\
\hline 1 & 125 & 55 & 74.68 & 215.77 & 0.82282 \\
\hline 2 & 125 & 50 & 74.062 & 261.43 & 1.0455 \\
\hline 3 & 125 & 45 & 72.584 & 232.81 & 1.0477 \\
\hline 4 & 125 & 40 & 70.88 & 244.73 & 1.0887 \\
\hline 5 & 120 & 55 & 73.683 & 223.72 & 0.91603 \\
\hline 6 & 120 & 50 & 71.991 & 260.49 & 1.0289 \\
\hline 7 & 120 & 45 & 69.462 & 265.03 & 0.94255 \\
\hline 8 & 120 & 40 & 67.725 & 247.03 & 1.0953 \\
\hline 9 & 115 & 55 & 68.334 & 244.47 & 0.99954 \\
\hline 10 & 115 & 50 & 66.461 & 256.2 & 1.0844 \\
\hline 11 & 115 & 45 & 64.18 & 243.51 & 1.1525 \\
\hline 12 & 115 & 40 & 62.489 & 254.19 & 1.1187 \\
\hline 13 & 110 & 55 & 63.71 & 239.01 & 1.0379 \\
\hline 14 & 110 & 50 & 62.084 & 241.33 & 1.0701 \\
\hline 15 & 110 & 45 & 60.433 & 252.46 & 1.1814 \\
\hline 16 & 110 & 40 & 58.124 & 264.44 & 1.1166 \\
\hline 17 & 105 & 55 & 59.574 & 234.94 & 1.1084 \\
\hline 18 & 105 & 50 & 57.812 & 278.61 & 1.2393 \\
\hline 19 & 105 & 45 & 56.992 & 251.13 & 1.184 \\
\hline 20 & 105 & 40 & 56.13 & 274.53 & 1.1681 \\
\hline 21 & 100 & 55 & 57.97 & 256.85 & 1.1071 \\
\hline 22 & 100 & 50 & 57.10 & 268.37 & 1.1983 \\
\hline 23 & 100 & 45 & 56.27 & 268.34 & 1.1779 \\
\hline 24 & 100 & 40 & 55.417 & 288.53 & 1.2719 \\
\hline
\end{tabular}


Table 3. Comparison of the best three candidates.

\begin{tabular}{|l|l|l|l|l|l|}
\hline & $\begin{array}{l}\text { Width, D } \\
(\mathrm{mm})\end{array}$ & $\begin{array}{l}\text { Width, d } \\
(\mathrm{mm})\end{array}$ & $\begin{array}{l}\text { Mass } \\
(\mathrm{kg})\end{array}$ & Stress (MPa) & $\begin{array}{l}\text { Displacement } \\
(\mathrm{mm})\end{array}$ \\
\hline Candidate No. 1 & 100 & 40 & 55.417 & 288.53 & 1.2719 \\
\hline Candidate No. 2 & 100 & 45 & 56.27 & 268.34 & 1.1779 \\
\hline Candidate No. 3 & 105 & 40 & 56.13 & 274.53 & 1.1681 \\
\hline
\end{tabular}

The contour plots of equivalent (von-mises) stress and deformation for the best three candidates obtained are shown below.Colour scale in the deformation contour plots shows the variation in the deformation. It is observed that maximum deformation occurs at the endtip section of the cranehook which is shown red in colour. The values of deformation achieved are very less and practically acceptable. Colour scale in the stress contour plots shows the variation in the equivalent (von mises) stress. It is a key for identifying areas of potential concern in a model. The regions bearing the maximum stress shown red in colour and regions of the crane hook bearing little or no load are shown blue in colour. A slight increase in the deformation and stress levels as compared to the actual model is noticed but it is safe and practically acceptable.

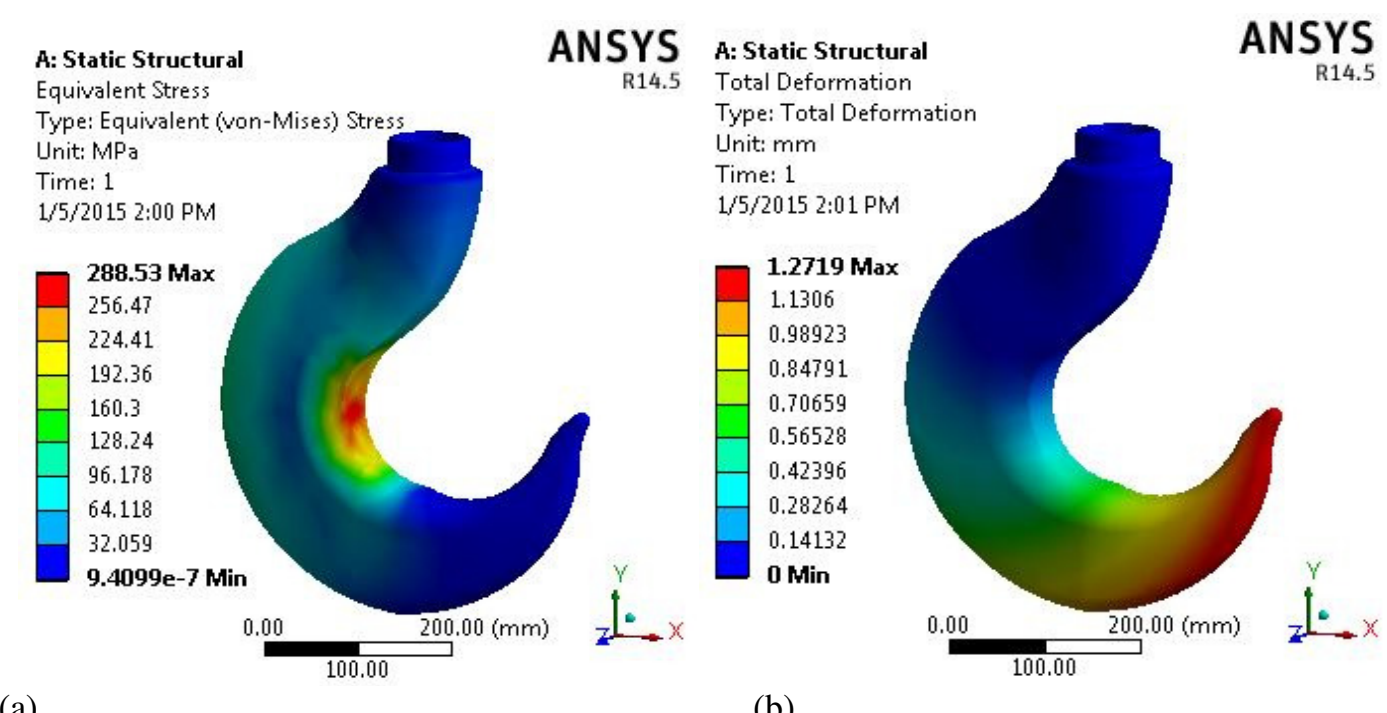

(a)

(b)

Fig. 6 Equivalent (von-mises) stress and Total deformation of crane hook having $D=100 \mathrm{~mm} \& \mathrm{~d}=40 \mathrm{~mm}$. 


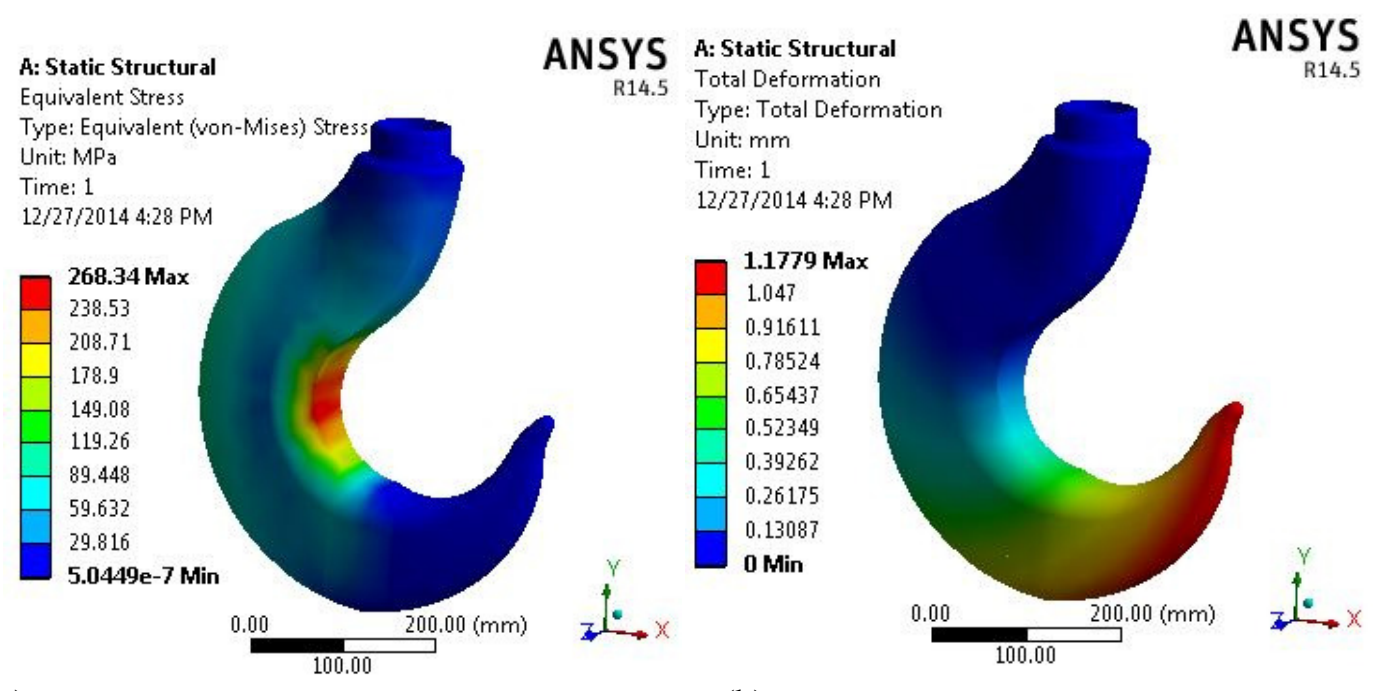

(a)

(b)

Fig.7 Equivalent (von-mises) stress and Total deformation of crane hook having $D=100 \mathrm{~mm} \& \mathrm{~d}=45 \mathrm{~mm}$.

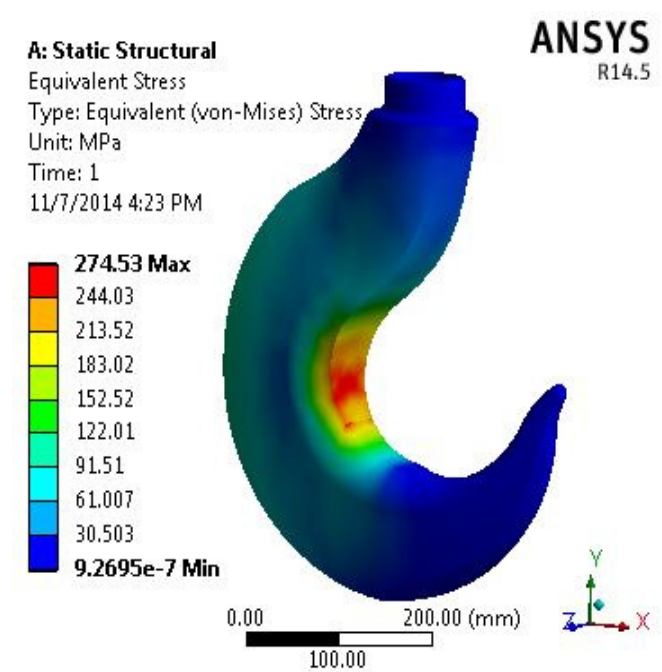

(a)

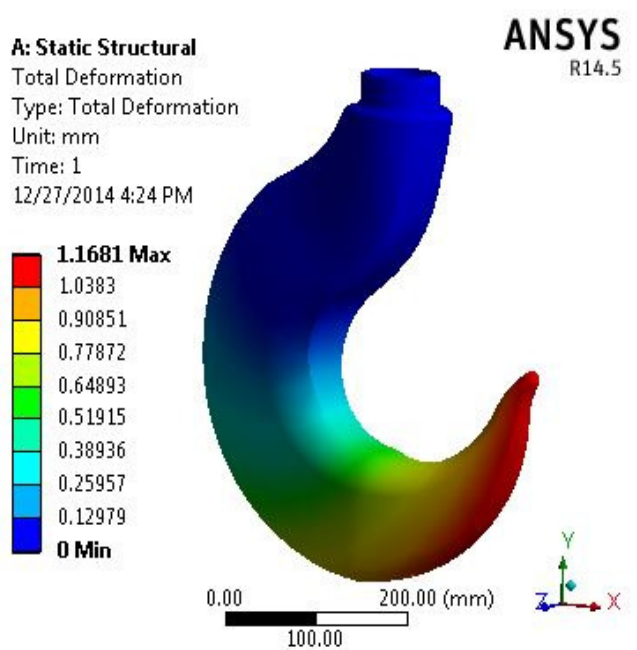

(b)

Fig.8 Equivalent (von-mises) stress and Total deformation of crane hook having $\mathrm{D}=105 \mathrm{~mm} \& \mathrm{~d}=40 \mathrm{~mm}$.

\subsection{Fatigue Analysis}

Fatigue analysis is carried out for the actual model and the best 3 candidates obtained and two fatigue contours are plotted. The two contour plots are fatigue life and fatigue damage. In the present study, the type of load mapping used for fatigue analysis is constant amplitude load mapping. Constant amplitude load mapping assumes FE stress/strain results to cycle between minimum and maximum values. The nCode DesignLife SN constant amplitude load mapping engine is drag onto the solution cell of themechanical system to generate file.rst file which reads node \& element information and FE stress/strain results as shown in fig. 9. 


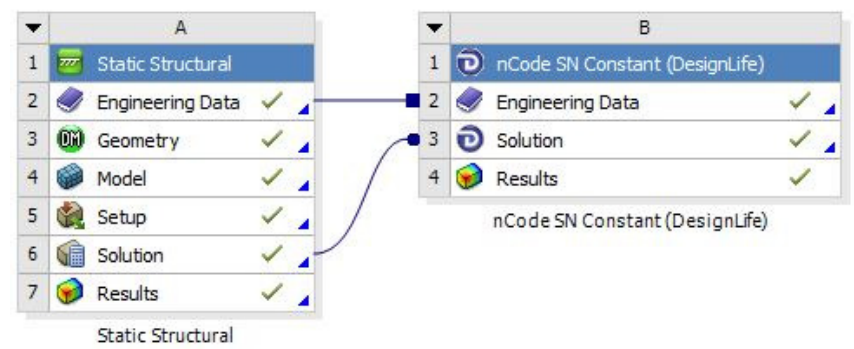

Fig.9 Project Schematic.

\subsubsection{Fatigue Analysis Results}

The available life for a specified fatigue analysis is given by the fatigue life contour plot. The contour plots of fatigue lifeof the actual model and the best three candidates obtained are shown below. It shows the number of cycles the crane hook can withstand before fatigue failure. The minimum fatigue life of the actual crane hook model is $9.104 \mathrm{E}^{7}$ repeats as shown in fig. 10.The comparison of the fatigue life of each candidate is shown in table 4. Figures given below show contour plots of the fatigue damage of the actual hook and the best three candidates obtained. It is noticed that the maximum fatigue damage occurs at the inner section of the crane hooks. The variation in fatigue damage of the crane hook is shown by the colour scale. The comparison of fatigue damage of each crane hook is shown in table 4.

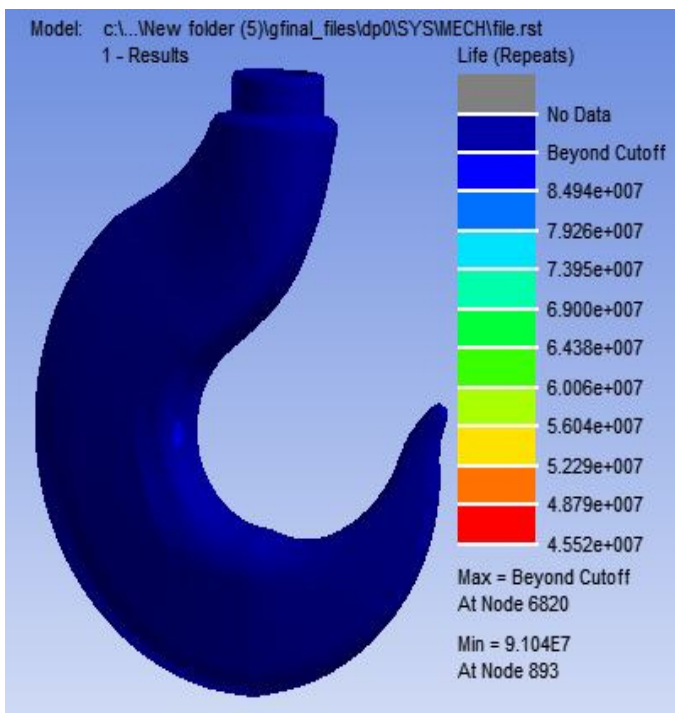

(a)

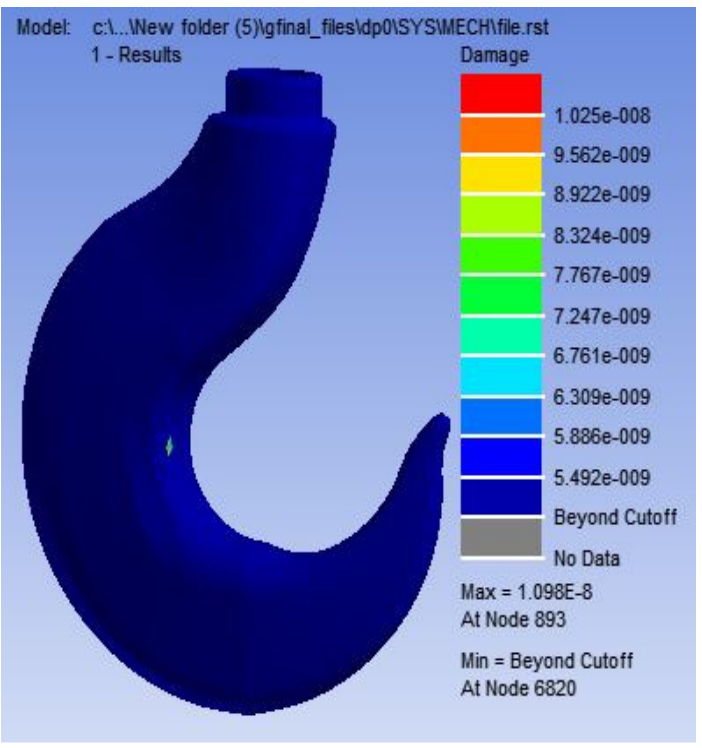

(b)

Fig. 10 Fatigue life and damage contour plots of actual crane hook. 
International Journal of Recent advances in Mechanical Engineering (IJMECH) Vol.4, No.4, November 2015

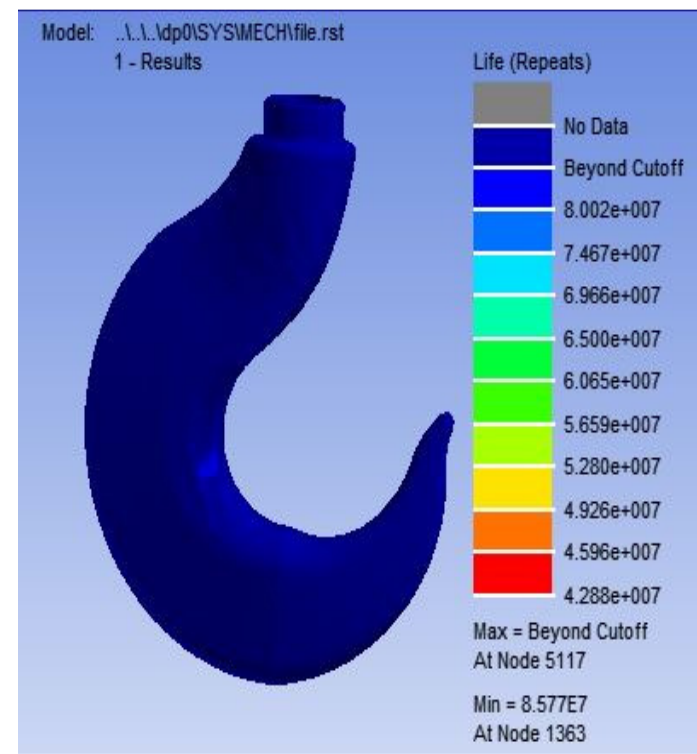

(a)

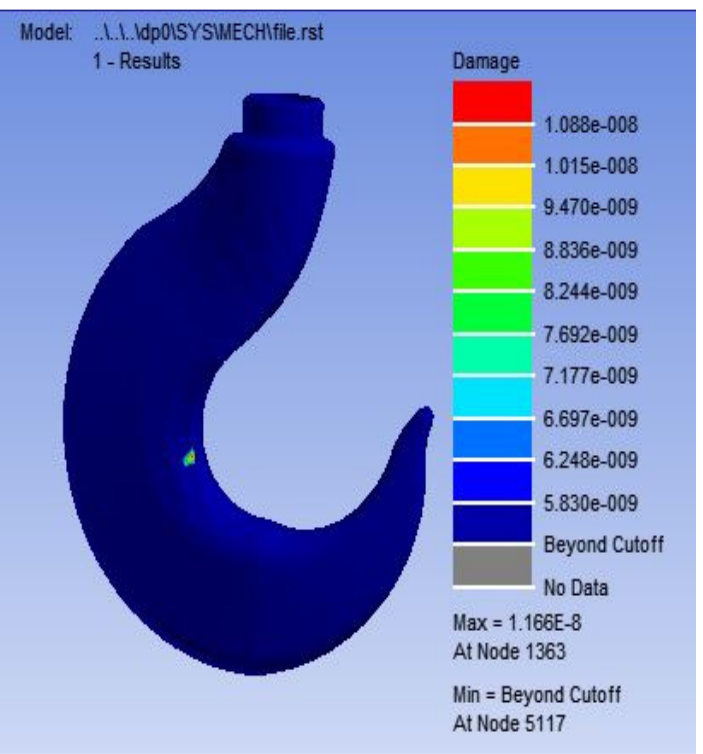

(b)

Fig. 11 Fatigue life and damage contour plots of crane hook having $D=100 \mathrm{~mm}, \mathrm{~d}=40 \mathrm{~mm}$.
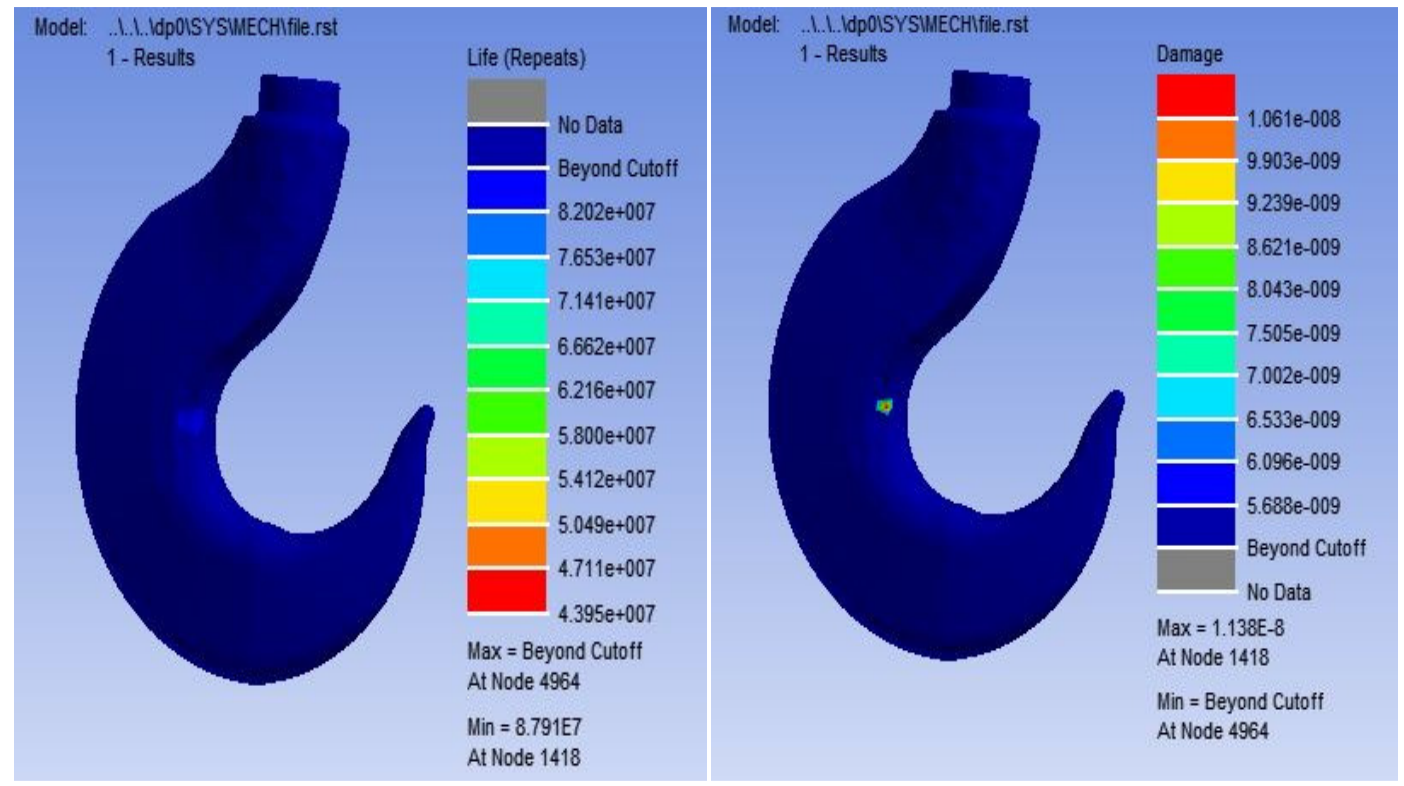

(a)

(b)

Fig. 12 Fatigue life and damage contour plots of crane hook having $D=100 \mathrm{~mm}, \mathrm{~d}=45 \mathrm{~mm}$. 

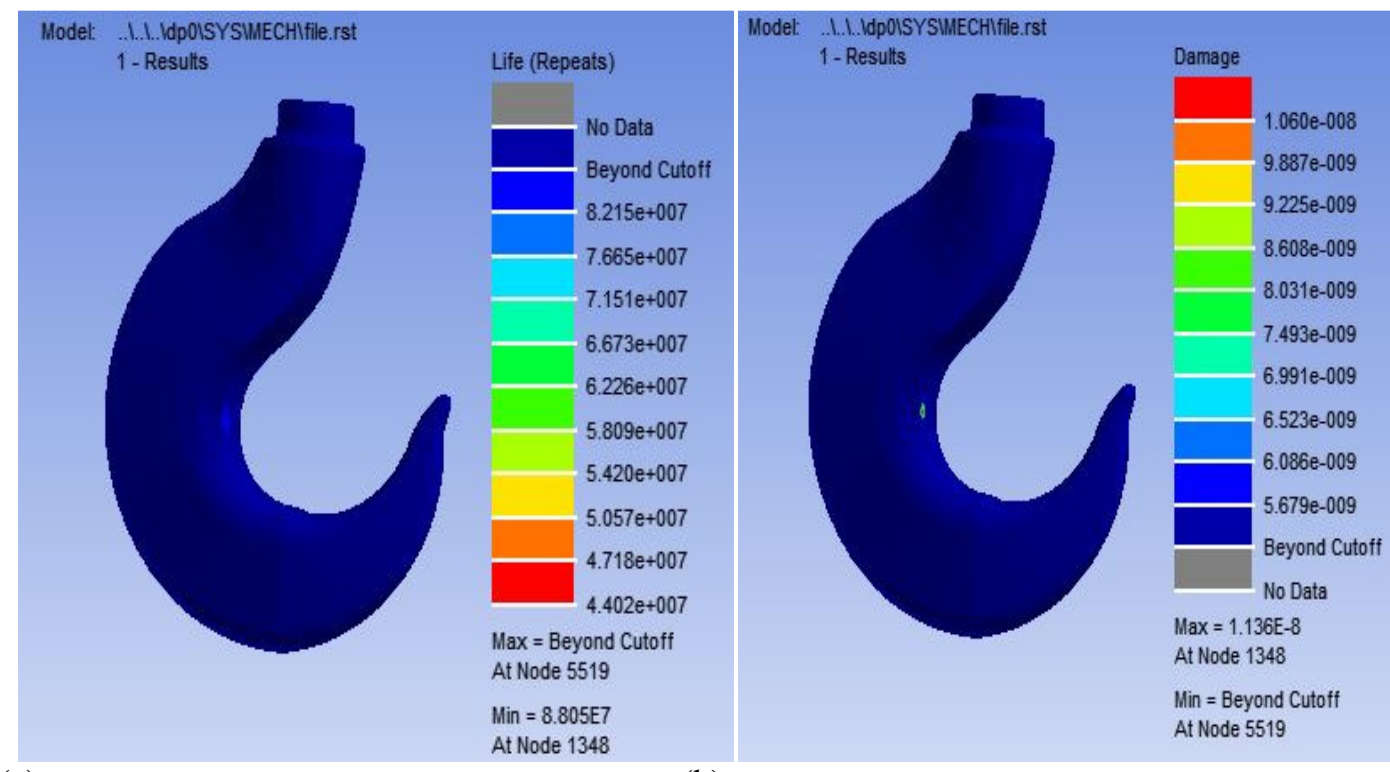

(a)

(b)

Fig.13 Fatigue life and damage contour plots of crane hook having $D=105 \mathrm{~mm}, \mathrm{~d}=40 \mathrm{~mm}$.

Table 4. Comparison of fatigue results of the actual model and the best three candidates.

\begin{tabular}{|l|l|l|l|l|l|}
\hline & $\begin{array}{l}\text { Width,D } \\
(\mathrm{mm})\end{array}$ & $\begin{array}{l}\text { Width,d } \\
(\mathrm{mm})\end{array}$ & $\begin{array}{l}\text { Mass } \\
(\mathrm{Kg})\end{array}$ & $\begin{array}{l}\text { Minimum Fatigue } \\
\text { Life (repeats) }\end{array}$ & $\begin{array}{l}\text { Maximum Fatigue } \\
\text { Damage }\end{array}$ \\
\hline $\begin{array}{l}\text { Actual } \\
\text { model }\end{array}$ & 120 & 50 & 71.991 & $9.104 \mathrm{E}^{7}$ & $1.098 \mathrm{E}^{-8}$ \\
\hline $\begin{array}{l}\text { Candidate } \\
\text { No. 1 }\end{array}$ & 100 & 40 & 55.417 & $8.577 \mathrm{E}^{7}$ & $1.66 \mathrm{E}^{-8}$ \\
\hline $\begin{array}{l}\text { Candidate } \\
\text { No. 2 }\end{array}$ & 100 & 45 & 56.27 & $8.79 \mathrm{E}^{7}$ & $1.138 \mathrm{E}^{-8}$ \\
\hline $\begin{array}{l}\text { Candidate } \\
\text { No. 3 }\end{array}$ & 105 & 40 & 56.13 & $8.805 \mathrm{E}^{7}$ & $1.136 \mathrm{E}^{-8}$ \\
\hline
\end{tabular}

On the basis of fatigue analysis results obtained, Candidate No.3 can withstand the maximum number of fatigue cycles before failure i.e., the minimum fatigue life obtained is $8.805 \mathrm{E}^{7}$ repeats which is better than the other two candidates.

\section{CONCLUSION}

In the present work, the geometry of the crane hook is modelled and finite element analysis (FEA) is applied on the model. The results of static structure analysis are obtained from the FEA software Ansys for different cross sections. In this study, we finally conclude that out of 24 candidates obtained, 3 best candidates are considered on the basis of minimum weight criteria. As a result, weight of crane hook is reduced for the same load. This will help in cost reduction and balance economy. Fatigue analysis is performed on thefinal 3 candidates using Ansys nCode Designlife. As a result, 1 candidate is selected on the basis of fatigue analysis having maximum fatigue life and it is compared with the actual crane hook model as shown in table 5. 
Table. 5 Comparison of the actual crane hook model and the best candidate obtained after weight optimization.

\begin{tabular}{|l|l|l|}
\hline Parameters & $\begin{array}{l}\text { Actual } \\
\text { Model }\end{array}$ & Candidate No.3 \\
\hline Width, D(mm) & 120 & 105 \\
\hline Width, d(mm) & 50 & 40 \\
\hline Mass (Kg) Stress (von-mises) & 71.991 & 56.13 \\
\hline $\begin{array}{l}\text { Equivalent } \\
\text { (MPa) }\end{array}$ & 1.0289 .49 & 274.53 \\
\hline Deformation (mm) & 1.1681 \\
\hline Minimum Fatigue Life (repeats) & $9.104 \mathrm{E}^{7}$ & $8.805 \mathrm{E}^{7}$ \\
\hline Maximum Fatigue Damage & $1.098 \mathrm{E}^{-8}$ & $1.136 \mathrm{E}^{-8}$ \\
\hline
\end{tabular}

The weight of the final candidate is reduced by $15.861 \mathrm{Kg}$ compared to actual hook model. The weight optimization of the crane hook is achieved by taking parallel sides of the cross section of crane hook as the design variables. The minimum fatigue life of the final candidate obtained is decreased and stress value is increased by $14.04 \mathrm{MPa}$ which is within limits and practically acceptable. The weight of the hook is reduced by $22.03 \%$ which can be accepted as a optimize result.

\section{REFERENCES:}

[1] Lampman, S.R. editor, "ASM Handbook: Volume 19, Fatigue and Fracture", ASM International (1996)

[2] B. Nagaraju, M. Rajaroy, P. Venkatesh Reddy, K. Satyanarayana, "Stress Analysis of Crane Hook Using FEA", International Journal of Current Engineering And Scientific Research (IJCESR), 23940697, Volume-2, ISSUE-2,2015

[3] Yung-Li Lee, Jwo Pan, Richard Hathaway, Mark Barkey, "Fatigue Testing and Analysis", Butterworth-Heinemann, 1 edition, 2011.

[4] S.L. Kakani, Amit Kakani, "Material Science", New Age International Publishers.

[5] ASM Handbook Committee, "Heat Treating", published in 1991 as Volume 4 of the ASM Handbook.

[6] M.R. Mitchell, O. Buck, "Cyclic Deformation, Fracture and Nondestructive Evaluation of Advanced Materials", Volume 1, ASTM Publications.

[7] DesignLife Theory Guide and Help

[8] Huei-Huang Lee, "Finite element Simulations with Ansys Workbench 15", SDC publications.

[9] Raymond Browell, Al Hancq, "Calculating and Displaying Fatigue Results", Release 10.0 SPI, March 20, 2006.

[10] P.S. Gill, “A Textbook of Machine Drawing”, Table: Surface texture roughness, Page No.304, S.K. Kataria \& Sons.

[11] Tr. E. Haibach, "Analytical Strength Assessment of Components in Mechanical Engineering”, 2003, FKM Guideline.

[12] Spasoje Trifkovic' et al, "Stress analysis of crane hook using FEM", INFOTEH-JAHORINA Vol. 10, Ref. C-2, p. 244- 248, March 2011.

[13] Y. Torres, J.M. Gallardo, J. Dominguez, F.J. Jimenez E, "Brittle fractures of a crane hook", Engineering Failure Analysis 17 (2010) 38-47.

[14] Nishant Soni,"crane-hook shapes optimization and thermal analysis using finite element too" in international journal of advanced and innovation research", ISSN: 2278-7844.

[15] Pradyumnakesharimaharana, "Computer Aided Analysis and Design of Hoisting Mechanism of an EOT Crane”, Thesis, National Institute of Technology Rourkela, May-2012.

[16] Mr. A. Gopichand, Ms. R.V.S Lakshmi, Mr. B. Maheshkrishna, "Optimization of design parameter for crane hook using taguchi method" in international journals of innovative research in science, engineering and technology, vol. 2, Dec 2013, ISSN: 2319-8753. 
[17] Er. R.K. Rajput, "Strength of Materials", Mechanics of Solids, Revised Edition, S. Chand \& Company Ltd.

\section{Authors}

Amandeep Singh I am a student of B.E. in Mechanical Engineering from Chandigarh College of Engineering and technology, Sector 26, Chandigarh. I did my industrial training in Mahindra \& Mahindra Swaraj Tractors, Mohali, Punjab. For the last 3 years, I am involved in product development projects involving use ofCAE softwares like Ansys nCode DesignLife \& Ansys Workbench and CAD softwares like Catia V5, Pro-E, Solidworks \&

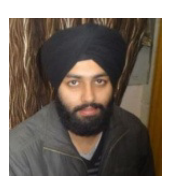
AutoCAD. I have worked as a roll cage design, static \& fatigue analysis engineer in SAE MINI BAHA in 2014. My keen areas of interest are durability analysis \& testing and process optimization.Some of my projects are:

- Did reverse engineering on wheel rim and designed, optimized and performed durability analysis using Duty cycle Load mapping on it using solidworks and Ansys (structure \& nCode in particular) from March 2015 to May 2015.

- Designed NACA 4412 using Visual Foil 5.0 as a Mini Project in 5th semester.

- Did SN fatigue analysis of a mountain bike frame as a Mini Project in 6th semester.

Mr. Vinod Rohilla is presently working at Chandigarh College of Engineering and technology, Sector 26, Chandigarh as an Assistant Professor in Department of Mechanical Engineering. He is Pursuing PhD from YMCA University of Science and Technology, Faridabad, Haryana. He has 8 years of teaching experience and 5 years of industrial experience. 